\title{
GENETIC DIVERSITY AMONG THYMUS SPP. USING RAPD AND ISSR MARKERS
}

\author{
Esraa A. El Sherbeny*, El-Shaimaa S. El-Demerdash, Yasser A.M. \\ Salama and Mohamed Z.S. Ahmed \\ ${ }^{1}$ Department of Genetic Resources, Desert Research Center, El-Matareya, Cairo, \\ Egypt \\ *E-mail: esraaelsherbeny2@gmail.com
}

$\mathrm{T}$ his investigation was carried out to assess the relationships among three Thymus species; two wild species (Thymus capitatus and Thymus decussatus) and a cultivar (Thymus vulgaris). Two molecular markers were used to determine the genetic relationships among them; random amplified polymorphic DNA (RAPD) and the inter-simple sequence repeats (ISSR) markers techniques. The results suggest that RAPD marker is the best choice for the evaluation of diversity and the genetic relationships between two wild Thymus species with high accuracy, which revealed 224 DNA bands detected across 15 primers with high polymorphism than ISSR, which revealed 336 DNA bands. The genetic relationship among Thymus species based on molecular data was developed using a dendrogram constructed by UPGMA cluster analysis. Conservationist may use the information of the present study to make effective decisions regarding the global protection and management of Thymus species in Egypt.

Keywords: Thymus, genetic relationships, RAPD-PCR, ISSR

The genus Thymus belongs to the family Lamiaceae and includes several hundreds of species distributed over the world (Akcin, 2006). The systematics of species remains difficult because of the interspecific hybridization, polyploidy and morphological similarities among species (Morales, 1996 and Tzakow and Constantinidis, 2005). The genus Thymus is known in several countries as a spice and food preservative, as well as a

The $1^{\text {st }}$ Scientific Conference of Plant Genetic Resources Department, Ecology and Dry Lands Agriculture Division, Desert Research Center "Plant Genetic Resources and Sustainable Development Under Egyptian Desert Conditions" 13-16 November, 2019, Sharm El-Sheikh, South Sinai, Egypt 
protective and curative remedy for many ailments. In the present study, RAPD and ISSR markers were used to characterize and determine the percentage of genetic diversity between three Egyptian species of Thymus and evaluate their genetic relationships. These methods are broadly used in plant population genetics and differentiation studies (Monteleone et al., 2006; Solouki et al., 2008 and Trindade et al., 2009). Generally, RAPD has allowed the resolution of complex taxonomic relationships (Casiva et al., 2002 and Ruana et al., 2004) and phylogenetic studies (Mariette et al., 2007). ISSR marker permits detection of polymorphisms in inter- microsatellite loci, using a primer designed from dinucleotide or trinucleotide simple sequence repeats. ISSR amplifies inter-microsatellite sequences at multiple loci throughout the genome (Li and Xia, 2005). DNA-based molecular markers, which are not affected by environmental conditions, have become increasingly important for surveying genetic diversity and genotype identification of medicinal plants (Nybom and Weising, 2007). These markers can also be taxonomically useful, i.e. for phylogenetic studies to distinguish plant species and subspecies (Mulcahy et al., 1995; Baigi et al., 2009 and Alamdary et al., 2011). In this research study, RAPD and ISSR were used to assess the genetic diversity among selected Thymus species, two grown naturally in Egypt (Thymus capitatus L. and Thymus decussatus Benth.) and a cultivar (Thymus vulgaris).

\section{MATERIALS AND METHODS}

\section{Plant Material Collection}

All The plants species in this study were kindly identified by members from Department of Ecology and Range Management, Desert Research Center. The plant leaf samples were collected in spring 2018, kept frozen in $80^{\circ} \mathrm{C}$. The frozen leaves of all plant species were ground into fine powder using liquid nitrogen. Samples of the first species; Thymus capitatus (a type of wild thyme) were collected from naturally grown rocky ridge habitats, especially wet sites distributed on North coast, Mersa Matruh governorate. Samples of the second species; Thymus decussatus (a type of wild thyme) was collected from Saint Katherine Protectorate, South Sinai governorate. The plant is a chasmophyte growing in rocky areas, especially wet sites. The samples of the last species; Thymus vulgaris (a cultivar plant) were collected from farmers in Kirdasa, Giza governorate. In addition to the thyme species; Origanum vulgare that was introduced to this study as a random outgroup (control). Leaves of each species were used as source of DNA in this research study.

Egyptian J. Desert Res., 69, Special Issue, 91-106 (2019) 


\section{Extraction and Purification of Genomic DNA}

Genomic DNAs were extracted from young leaves of the three species of Thymus as well as Origanum vulgare by DNeasy Plant Mini Kit (Qiagen Inc., Cat.no.69104, USA), and was performed following the manufacturer's instruction.

\section{Estimation of DNA Concentration}

The concentrations and quality of the genomic DNA samples were estimated using ND-2000 spectrophotometer (Nanodrop, USA). Finally, all the genomic DNA samples were diluted to a final concentration of $40 \mathrm{ng} / \mu \mathrm{l}$ with TE buffer (10 mM Tris-HC1, $\mathrm{pH} 8.0 ; 1$ $\mathrm{mM}$ EDTA) and stored at $-20^{\circ} \mathrm{C}$ for further use.

\section{ISSR and RAPD Analysis \\ 4.1. Primers Selection and ISSR-PCR and RAPD-PCR Reactions}

Twenty ISSR and Fifteen RAPD primers were selected to be tested for the ability to generate DNA polymorphism among six samples of the three different Thymus species and one sample of Origanum vulgare as control (an outgroup). These primers were synthesized by Metabion Corp., Germany. The primers code and nucleotide sequences are presented table (1 and 2). The PCR amplification reactions were performed in $25 \mu \mathrm{l}$ volume composed of $2.5 \mu \mathrm{l}$ (1x ) reaction buffer, $0.5 \mu \mathrm{l}(0.2 \mathrm{mM}) \mathrm{dNTPs}, 2 \mu \mathrm{l}(1.5 \mathrm{mM}) \mathrm{MgCl}_{2}, 1 \mu \mathrm{l}(0.2$ $\mu \mathrm{M})$ primer, $1 \mu \mathrm{l}$ (0.5 unit) Taq polymerase (Qiagen Ltd., Germany) and 50 ng of template DNA, in sterile distilled water.

\section{ISSR and RAPD-Thermocycling Profile and Detection of the PCR Products}

PCR amplification of the DNA was performed in a Perkin Elmer thermal cycler 9700 . The temperature profile in the different cycles was as follows: an initial strand separation cycle at $94^{\circ} \mathrm{C}$ for $5 \mathrm{~min}$, followed by 40 cycles comprised of a denaturation step at $94^{\circ} \mathrm{C}$ for $1 \mathrm{~min}$, an annealing step at $45^{\circ} \mathrm{C}$ for $1 \mathrm{~min}$ and an extension step at $72^{\circ} \mathrm{C}$ for $1.5 \mathrm{~min}$. The final cycle was a polymerization cycle for $7 \mathrm{~min}$ at $72^{\circ} \mathrm{C}$.

PCR products were mixed with $5 \mu 1$ gel loading dye and resolved by electrophoresis in a $1.5 \%$ agarose gel containing ethidium bromide $(0.5$ $\mathrm{mg} / \mathrm{ml}$ ) in $1 \times$ TBE buffer at 120 volts. A $100 \mathrm{bp}$ DNA ladder was used as molecular size standard. PCR products were visualized under UV light and documented using a TMXR+ Gel Documentation System (Bio-Rad). 
Table (1). List of the twenty selected ISSR primers for polymorphic DNA generation of Thymus species.

\begin{tabular}{|c|c|c|}
\hline No. & Primer & Sequence \\
\hline 1 & UBC-824 & $(\mathrm{TC})_{8} \mathrm{G}$ \\
\hline 2 & UBC-826 & $(\mathrm{AC})_{8} \mathrm{C}$ \\
\hline 3 & UBC- 827 & $(\mathrm{AC})_{8} \mathrm{G}$ \\
\hline 4 & UBC-834 & $(\mathrm{AG})_{8} \mathrm{TT}$ \\
\hline 5 & UBC- 852 & $(\mathrm{TC})_{8} \mathrm{AA}$ \\
\hline 6 & UBC-868 & $(\mathrm{GAA})_{6}$ \\
\hline 7 & UBC-876 & $(\text { GATA })_{2}(\text { GACA })_{2}$ \\
\hline 8 & UBC- 880 & $(\text { GGAGA })_{3}$ \\
\hline 9 & 814A & $(\mathrm{CT})_{8} \mathrm{TG}$ \\
\hline 10 & $844 \mathrm{~A}$ & $(\mathrm{CT})_{8} \mathrm{AC}$ \\
\hline 11 & HB08 & $(\mathrm{GA})_{6} \mathrm{GG}$ \\
\hline 12 & HB10 & $(\mathrm{GA})_{6} \mathrm{CC}$ \\
\hline 13 & HB12 & $(\mathrm{CAC})_{3} \mathrm{GC}$ \\
\hline 14 & HB13 & $(\mathrm{GAG})_{3} \mathrm{GC}$ \\
\hline 15 & HB14 & $(\mathrm{CTC})_{3} \mathrm{GC}$ \\
\hline 16 & ISSR- 11 & $(\mathrm{AC})_{8} \mathrm{YA}$ \\
\hline 17 & ISSR- 12 & $(\mathrm{AC})_{8} \mathrm{YC}$ \\
\hline 18 & ISSR- 13 & $(\mathrm{AG})_{8} \mathrm{YT}$ \\
\hline 19 & ISSR- 14 & $(\mathrm{CTC})_{5} \mathrm{TT}$ \\
\hline 20 & ISSR- 15 & $(\mathrm{CT})_{8} \mathrm{CG}$ \\
\hline
\end{tabular}

Table (2). List of the fifteen selected RAPD primers for polymorphic DNA generation of Thymus species.

\begin{tabular}{ccc}
\hline No. & Primer & Sequence \\
\hline $\mathbf{1}$ & OPA-05 & 5'-AGGGGTCTTG-3' \\
$\mathbf{2}$ & OPA-10 & 5'-GTGATCGCAG-3' \\
$\mathbf{3}$ & OPB-15 & 5'-GGAGGGTGTT-3' \\
$\mathbf{4}$ & OPD-05 & 5'-TGAGCGGACA-3' \\
$\mathbf{5}$ & OPD-19 & 5'-CTGGGGACTT-3' \\
$\mathbf{6}$ & OPE-01 & 5'-CCCAAGGTCC-3' \\
$\mathbf{7}$ & OPE-20 & 5'-AACGGTGACC-3' \\
$\mathbf{8}$ & OPF-03 & 5'-CCTGATCACC-3' \\
$\mathbf{9}$ & OPF-14 & 5'-TGCTGCAGGT-3' \\
$\mathbf{1 0}$ & OPH-02 & 5'-TCGGACGTGA-3' \\
$\mathbf{1 1}$ & OPA-07 & 5'-GAAACGGGTG-3' \\
$\mathbf{1 2}$ & OPA-08 & 5'-GTGACGTAGG-3' \\
$\mathbf{1 3}$ & OPB-12 & 5'-CCTTGACGCA-3' \\
$\mathbf{1 4}$ & OPB-17 & 5'-AGGGAACGAG-3' \\
$\mathbf{1 5}$ & OPB-18 & 5'-CCACAGCAGT-3' \\
\hline
\end{tabular}

Egyptian J. Desert Res., 69, Special Issue, 91-106 (2019) 


\section{Data Analysis}

DNA polymorphism generated by ISSR and RAPD-PCR were calculated based on the presence or absence of amplified bands were scored as present (1) or absent (0) across the Thymus species. The only clear major bands were subjected to scoring. The specific bands useful for identifying species were named with a primer number followed by the approximate size of the amplified fragment in base pairs. To construct a dendrogram describing the genetic relatedness of Thymus species, genetic distance was calculated based on the Jaccard coefficient (Jaccard, 1908), using the correlate module of SPSS software version 20, after making a pair wise comparison between them, relying on the proportion of shared bands that produced by each used primer. Jaccard's coefficients are common estimators of genetic identification, and were calculated as [Jaccard's coefficient = $\mathrm{NAB} /(\mathrm{NAB}+\mathrm{NA}+\mathrm{NB})]$; where $\mathrm{NAB}$ is the number of bands shared by samples, NA represents amplified fragments in sample A, and NB represents fragments in sample B. Similarity matrix based on these indices were calculated. This was used using classify module of SPSS software version19.

\section{RESULTS AND DISCUSSION}

Molecular markers are efficient tools for identification and estimation of relatedness through DNA fingerprinting. In the present investigation, two types of molecular markers namely, ISSR and RAPD were employed to assess the genetic polymorphism within and among two wild species; Thymus capitatus and Thymus decussatus and the cultivar Thymus vulgaris.

\section{Genetic Polymorphism as Detected by ISSR Markers}

The twenty ISSR primers amplified a total of 336 bands in the set of six samples of the three Thymus species and Origanum vulgare (Fig. 1). DNA polymorphisms generated by ISSR were calculated based on the presence or absence of amplified fragments. The number of bands for each primer ranged from 11 for primer $844 \mathrm{~A}$ to 25 for primer ISSR-12 with sequences of (CT) 8AC and 5'-ACACACACACACACACYC-3', respectively with an average of 16.8 at the species level. The percentage of polymorphic bands (PPB) was calculated based on Jaccard's coefficients to be ranged between 78 and 100\% with an average of $96.76 \%$ (Table 3 ). Such high level of polymorphism is comparable to the results of some similar molecular researches on medicinal plants of Lamiaceae family (Trindade et al., 2009 and Agostini et al., 2010). 


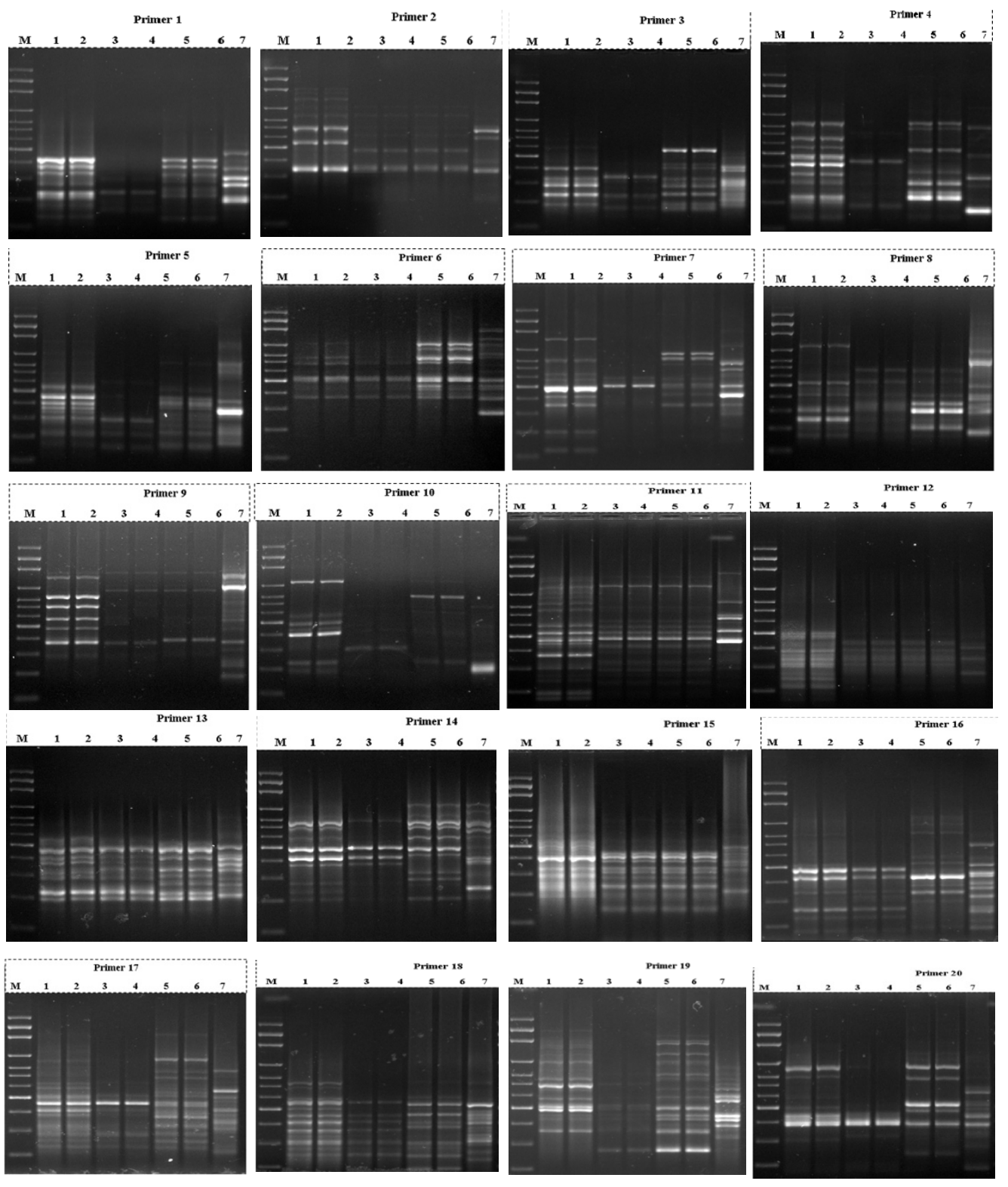

Fig. (1). Gel electrophoresis pattern of ISSR amplification using twenty primers. M: marker; (1 and 2) Thymus vulgaris, (3 and 4) Thymus capitatus, (5 and 6) Thymus decussatus and (7) Origanum vulgare.

Egyptian J. Desert Res., 69, Special Issue, 91-106 (2019) 
Table (3). The polymorphism generated by twenty ISSR primers for Thymus species.

\begin{tabular}{ccccccccc}
\hline No. & Primer & $\begin{array}{c}\text { Mono- } \\
\text { morphic } \\
\text { bands }\end{array}$ & $\begin{array}{c}\text { Polymorphic } \\
\text { (without } \\
\text { Unique) }\end{array}$ & $\begin{array}{c}\text { Unique } \\
\text { bands }\end{array}$ & $\begin{array}{c}\text { Polymorphic } \\
\text { (with Unique) }\end{array}$ & $\begin{array}{c}\text { Total } \\
\text { number } \\
\text { of bands }\end{array}$ & $\begin{array}{c}\text { Polymorphism } \\
\text { (\%) }\end{array}$ & $\begin{array}{c}\text { Mean of } \\
\text { band } \\
\text { frequency }\end{array}$ \\
\hline $\mathbf{1}$ & UBC-824 & 0 & 10 & 5 & 15 & 15 & 100 & 0.4 \\
$\mathbf{2}$ & UBC-826 & 1 & 9 & 5 & 14 & 15 & 93 & 0.4 \\
$\mathbf{3}$ & UBC-827 & 1 & 10 & 4 & 14 & 15 & 93 & 0.4 \\
$\mathbf{4}$ & UBC-834 & 0 & 16 & 2 & 18 & 18 & 100 & 0.4 \\
$\mathbf{5}$ & UBC-852 & 2 & 13 & 1 & 14 & 16 & 88 & 0.5 \\
$\mathbf{6}$ & UBC-868 & 3 & 7 & 8 & 15 & 18 & 83 & 0.5 \\
$\mathbf{7}$ & UBC-876 & 2 & 9 & 4 & 13 & 15 & 87 & 0.5 \\
$\mathbf{8}$ & UBC-880 & 2 & 10 & 3 & 13 & 15 & 87 & 0.5 \\
$\mathbf{9}$ & $814 A$ & 1 & 8 & 5 & 13 & 14 & 93 & 0.4 \\
$\mathbf{1 0}$ & $844 A$ & 0 & 9 & 2 & 11 & 11 & 100 & 0.4 \\
$\mathbf{1 1}$ & HB08 & 1 & 19 & 4 & 23 & 24 & 96 & 0.5 \\
$\mathbf{1 2}$ & HB10 & 2 & 10 & 1 & 11 & 13 & 85 & 0.5 \\
$\mathbf{1 3}$ & HB12 & 3 & 9 & 3 & 12 & 15 & 80 & 0.5 \\
$\mathbf{1 4}$ & HB13 & 3 & 9 & 4 & 13 & 16 & 81 & 0.6 \\
$\mathbf{1 5}$ & HB14 & 2 & 11 & 2 & 13 & 15 & 87 & 0.6 \\
$\mathbf{1 6}$ & ISSR-11 & 1 & 12 & 8 & 20 & 21 & 95 & 0.4 \\
$\mathbf{1 7}$ & ISSR-12 & 1 & 17 & 7 & 24 & 25 & 96 & 0.4 \\
$\mathbf{1 8}$ & ISSR-13 & 4 & 11 & 3 & 14 & 18 & 78 & 0.6 \\
$\mathbf{1 9}$ & ISSR-14 & 0 & 19 & 4 & 23 & 23 & 100 & 0.4 \\
$\mathbf{2 0}$ & ISSR-15 & 1 & 10 & 3 & 13 & 14 & 93 & 0.4 \\
& Total & 30 & 228 & 78 & 306 & 336 & 91 & \\
Mean per primer & 1.5 & 11.4 & 3.9 & 15.3 & 16.8 & 91 & \\
\hline
\end{tabular}

Data of ISSR profiles scanned from the six Thymus samples with twenty reproducible primers were used to generate similarity coefficients with Jaccard measure using SPSS software version19 (Table 4). Pairwise similarity of banding patterns between the studied plant species were ranged from 51 to $100 \%$ for species. The maximum similarity $(100 \%)$ was observed between Thymus vulgaris from different places. The lowest similarity value was observed between Thymus vulgaris and Thymus capitatus (51\%). Thymus capitatus showed the closest relationship with Thymus decussatus as a wild type. Origanum vulgare as an outgroup, confirmed the reliability of the ISSR method and similarity analysis tests to show quite divergent from other Thymus species with similarity coefficient range from 30 to $42 \%$ as shown in the similarity matrix (Table 4). Based on the Jaccard coefficient, the obtained distance coefficients were used to construct a dendrogram using classify

Egyptian J. Desert Res., 69, Special Issue, 91-106 (2019) 
module of SPSS software version19 (Fig. 2). The cluster tree analysis showed that Thymus species were divided into two main groups: the first group including Thymus decussatus, Thymus vulgaris and the second group including Thymus capitatus. However, Origanum vulgare was found to be quite divergent and did not fall in any of these two clusters.

Table (4). Genetic similarity (Jaccard's) for Thymus species and Origanum vulgare as an outgroup by ISSR pattern generated by Twenty ISSR primers

\begin{tabular}{|c|c|c|c|c|c|c|c|}
\hline Species & $\begin{array}{c}T . \\
\text { vulgaris }\end{array}$ & $\begin{array}{c}T . \\
\text { vulgaris }\end{array}$ & $\begin{array}{c}T . \\
\text { capitatus }\end{array}$ & $\begin{array}{c}T . \\
\text { capitatus }\end{array}$ & $\begin{array}{c}T . \\
\text { decussatus }\end{array}$ & $\begin{array}{c}T . \\
\text { decussatus }\end{array}$ & $\begin{array}{c}O . \\
\text { vulgare }\end{array}$ \\
\hline T. vulgaris & 100 & & & & & & \\
\hline T. vulgaris & 100 & 100 & & & & & \\
\hline T. capitatus & 51 & 52 & 100 & & & & \\
\hline T. capitatus & 51 & 52 & 100 & 100 & & & \\
\hline T. decussatus & 64 & 63 & 61 & 61 & 100 & & \\
\hline T. decussatus & 64 & 64 & 60 & 60 & 99 & 100 & \\
\hline O. vulgare & 41 & 42 & 30 & 30 & 39 & 38 & 100 \\
\hline
\end{tabular}

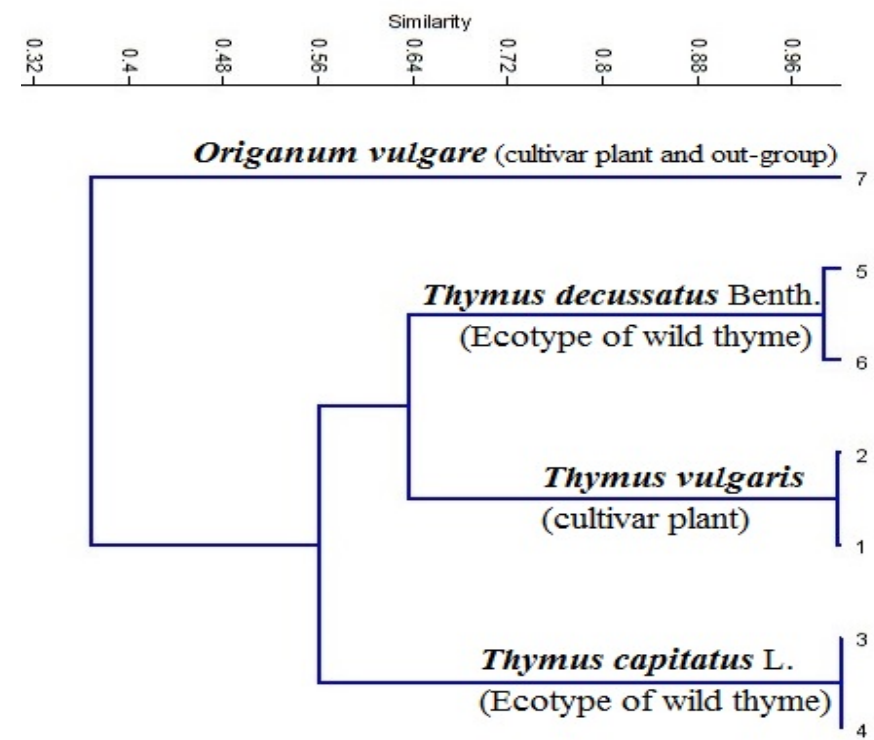

Fig. (2). The dendrogram cluster tree was generated for Thymus species where Origanum vulgare was used as an outgroup based on ISSR. (1 and 2) Thymus vulgaris, (3 and 4) Thymus capitatus, (5 and 6) Thymus decussatus and (7) Origanum vulgare.

Egyptian J. Desert Res., 69, Special Issue, 91-106 (2019) 


\section{Genetic Polymorphism as Detected by RAPD Markers}

The data obtained in the present study regarding RAPD molecular marker studies on the six samples of Thymus species reveal that RAPD marker is a good choice for assessing the genetic diversity and relationship in Thymus species with polymorphism levels enough to establish informative fingerprints with a few markers.

The fifteen primers used for all populations generated 224 bands in the set of the six samples of Thymus species and Origanum vulgare (Fig. 3). The bands ranged in size from 200 to $2000 \mathrm{bp}$. The number of bands produced by primers varied from 9 for primers OPE-01, OPH-02 and OPA-07 to 20 for primer OPE-20, with an average of 14.9 at the species level. The percentage of polymorphic loci per primer varied from $80 \%$ (OPE-20 and OPB-18) to 100\% (OPA-05, OPB-15, OPD-05, OPH-02, OPA-07 and OPA-08) (Table 5). Primers differed in their ability to distinguish individuals within and among populations. The highest number of RAPD fragments generated using the fifteen primers may be used as genotype-specific markers, when arranged in a descending order as follows, primer OPE-20 (four markers), primers OPA10, OPF-14, OPB-12 and OPB-18 (three markers), OPF-3 (two marker) and OPD-19, OPE-01 and OPB-17 (one marker), while the remaining primers had no genotype-specific markers. Thus, Thymus species could be identified by genotype-specific RAPD markers.

Table (6) shows similarity indices between the six samples of the three Thymus species. The highest value $(100 \%)$ was observed between Thymus vulgaris from different places, which indicate that these two populations are closely related to each other according to geographical distribution. On the other hand, the lowest similarity value $(60 \%)$ was observed between Thymus decussatus and the other species, indicating that they were distantly related. Based on Jaccard coefficient, the obtained distance coefficients were used to construct a dendrogram using classify module of SPSS software version 20 (Fig. 4). The cluster tree analysis showed that Thymus species were divided into two main groups: the first group including Thymus capitatus, Thymus vulgaris and the second group including Thymus decussatus. However, Origanum vulgare was found to be quite divergent and did not fall in any of these two clusters.

The results based on RAPD markers revealed a low level of variation within populations and high differentiation among them. The analysis of population genetic variation with RAPDs could be hampered by a loss of a part of genetic information (Khalil and Li, 2012 and Sunar et al., 2009).

Egyptian J. Desert Res., 69, Special Issue, 91-106 (2019) 

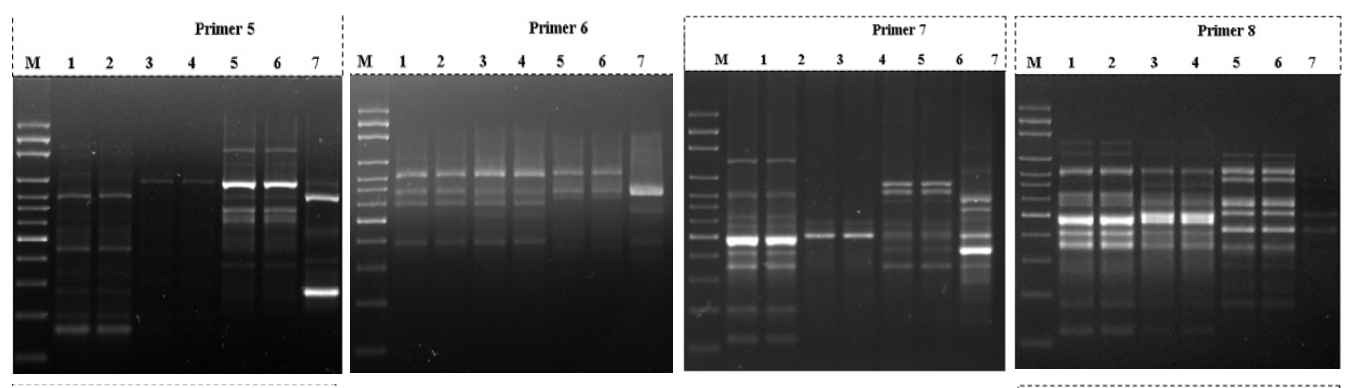

Primer 1

Primer 2

Primer 3

Primer 4
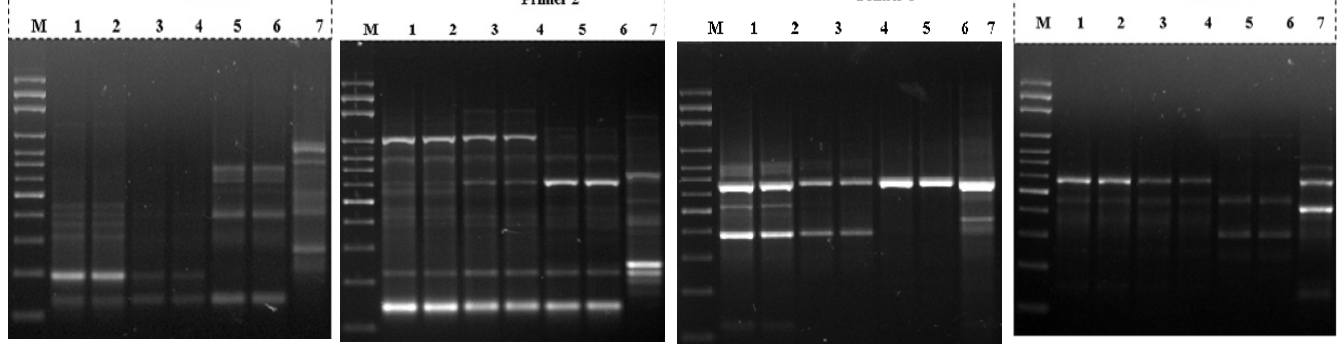

Primer 9

Primer 10

Primer 11

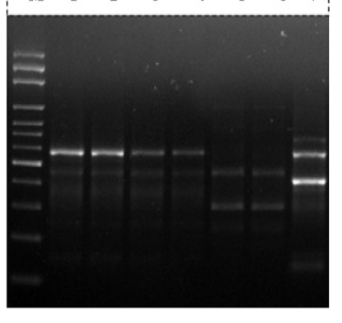

Primer 12
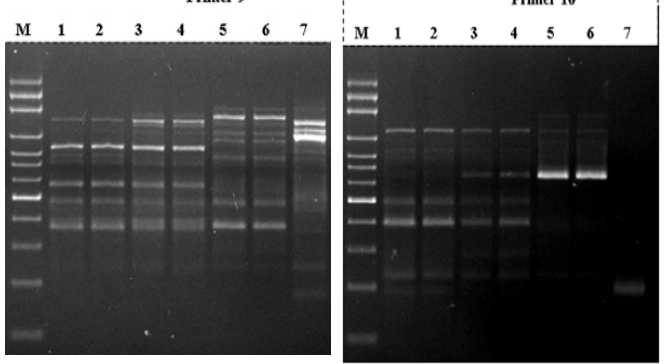

Primer 14
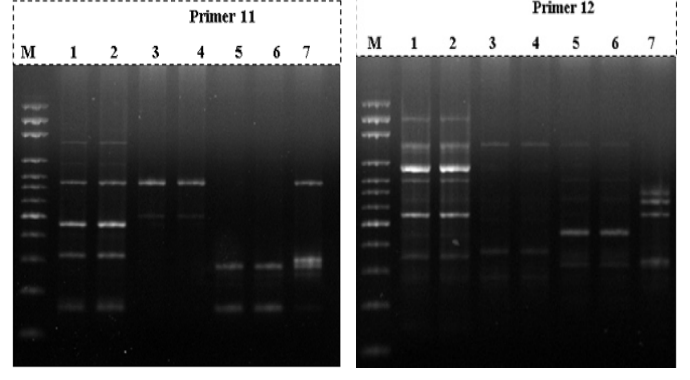

Primer 13
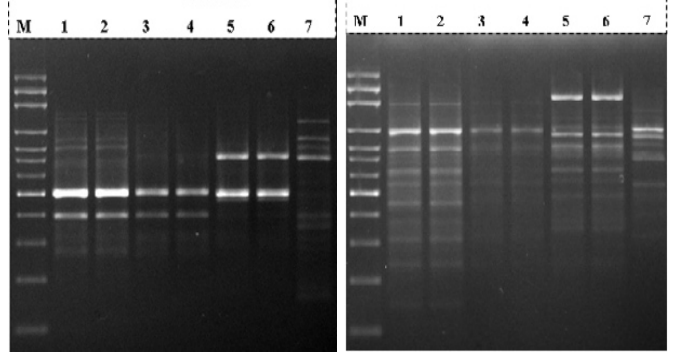

Primer 15

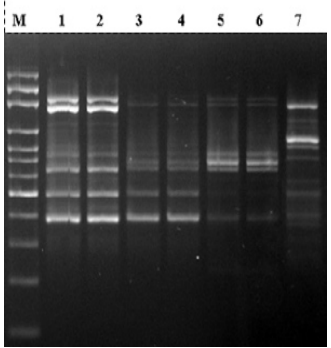

Fig. (3). RAPD amplification profiles obtained using fifteen primers analyzed in 1.5\% agarose gel electrophoreses. M: marker; (1 and 2) Thymus vulgaris, (3 and 4) Thymus capitatus, (5 and 6) Thymus decussatus and (7) Origanum vulgare.

Egyptian J. Desert Res., 69, Special Issue, 91-106 (2019) 
Table (5). The polymorphism generated by fifteen RAPD primers for Thymus species.

\begin{tabular}{ccccccccc}
\hline No. & Primer & $\begin{array}{c}\text { Monomorphic } \\
\text { bands }\end{array}$ & $\begin{array}{c}\text { Polymorphic } \\
\text { (without } \\
\text { unique) }\end{array}$ & $\begin{array}{c}\text { Unique } \\
\text { bands }\end{array}$ & $\begin{array}{c}\text { Polymorphic } \\
\text { (with } \\
\text { unique) }\end{array}$ & $\begin{array}{c}\text { Total } \\
\text { number } \\
\text { of bands }\end{array}$ & $\begin{array}{c}\text { Polymorphism } \\
\text { (\%) }\end{array}$ & $\begin{array}{c}\text { Mean of } \\
\text { band } \\
\text { frequency }\end{array}$ \\
\hline $\mathbf{1}$ & OPA-05 & 0 & 10 & 6 & 16 & 16 & 100 & 0.3 \\
$\mathbf{2}$ & OPA-10 & 3 & 8 & 8 & 16 & 19 & 84 & 0.5 \\
$\mathbf{3}$ & OPB-15 & 0 & 7 & 4 & 11 & 11 & 100 & 0.3 \\
$\mathbf{4}$ & OPD-05 & 0 & 7 & 6 & 13 & 13 & 100 & 0.4 \\
$\mathbf{5}$ & OPD-19 & 1 & 14 & 3 & 17 & 18 & 94 & 0.4 \\
$\mathbf{6}$ & OPE-01 & 1 & 6 & 3 & 9 & 9 & 90 & 0.5 \\
$\mathbf{7}$ & OPE-20 & 4 & 12 & 4 & 16 & 20 & 80 & 0.6 \\
$\mathbf{8}$ & OPF-03 & 2 & 17 & 2 & 19 & 21 & 90 & 0.6 \\
$\mathbf{9}$ & OPF-14 & 3 & 10 & 3 & 13 & 16 & 81 & 0.6 \\
$\mathbf{1 0}$ & OPH-02 & 0 & 9 & 0 & 9 & 9 & 100 & 0.6 \\
$\mathbf{1 1}$ & OPA-07 & 0 & 9 & 0 & 9 & 9 & 100 & 0.4 \\
$\mathbf{1 2}$ & OPA-08 & 0 & 13 & 2 & 15 & 15 & 100 & 0.4 \\
$\mathbf{1 3}$ & OPB-12 & 3 & 13 & 3 & 16 & 19 & 84 & 0.5 \\
$\mathbf{1 4}$ & OPB-17 & 1 & 10 & 3 & 13 & 14 & 93 & 0.5 \\
$\mathbf{1 5}$ & OPB-18 & 3 & 8 & 4 & 12 & 15 & 80 & 0.5 \\
& Total & 21 & 153 & 51 & 204 & 224 & & \\
Mean & per primer & 1.4 & 10.2 & 3.4 & 13.6 & 14.93 & & \\
\hline
\end{tabular}

Table (6). Genetic similarity (Jaccard's) among Thymus species and Origanum vulgare (an outgroup) by RAPD pattern generated by fifteen RAPD primers

\begin{tabular}{lccccccc}
\hline \multicolumn{1}{c}{ Species } & $\begin{array}{c}\boldsymbol{T} . \\
\text { vulgaris }\end{array}$ & $\begin{array}{c}\boldsymbol{T} \text {. } \\
\text { vulgaris }\end{array}$ & $\begin{array}{c}\boldsymbol{T} \text {. } \\
\text { capitatus }\end{array}$ & $\begin{array}{c}\boldsymbol{T} \text {. } \\
\text { capitatus }\end{array}$ & $\begin{array}{c}\boldsymbol{T} . \\
\text { decussatus }\end{array}$ & $\begin{array}{c}\boldsymbol{T} . \\
\text { decussatus }\end{array}$ & $\begin{array}{c}\text { O. } \\
\text { vulgare }\end{array}$ \\
\hline T. vulgaris & 100 & & & & & & \\
T. vulgaris & 100 & 100 & & & & & \\
T. capitatus & 70 & 68 & 100 & & & & \\
T. capitatus & 68 & 60 & 99 & 100 & & & \\
T. decussatus & 60 & 60 & 60 & 60 & 100 & & \\
T. decussatus & 60 & 64 & 60 & 60 & 100 & 100 & \\
O. vulgare & 38 & 38 & 32 & 30 & 36 & 36 & 100 \\
\hline
\end{tabular}

Egyptian J. Desert Res., 69, Special Issue, 91-106 (2019) 


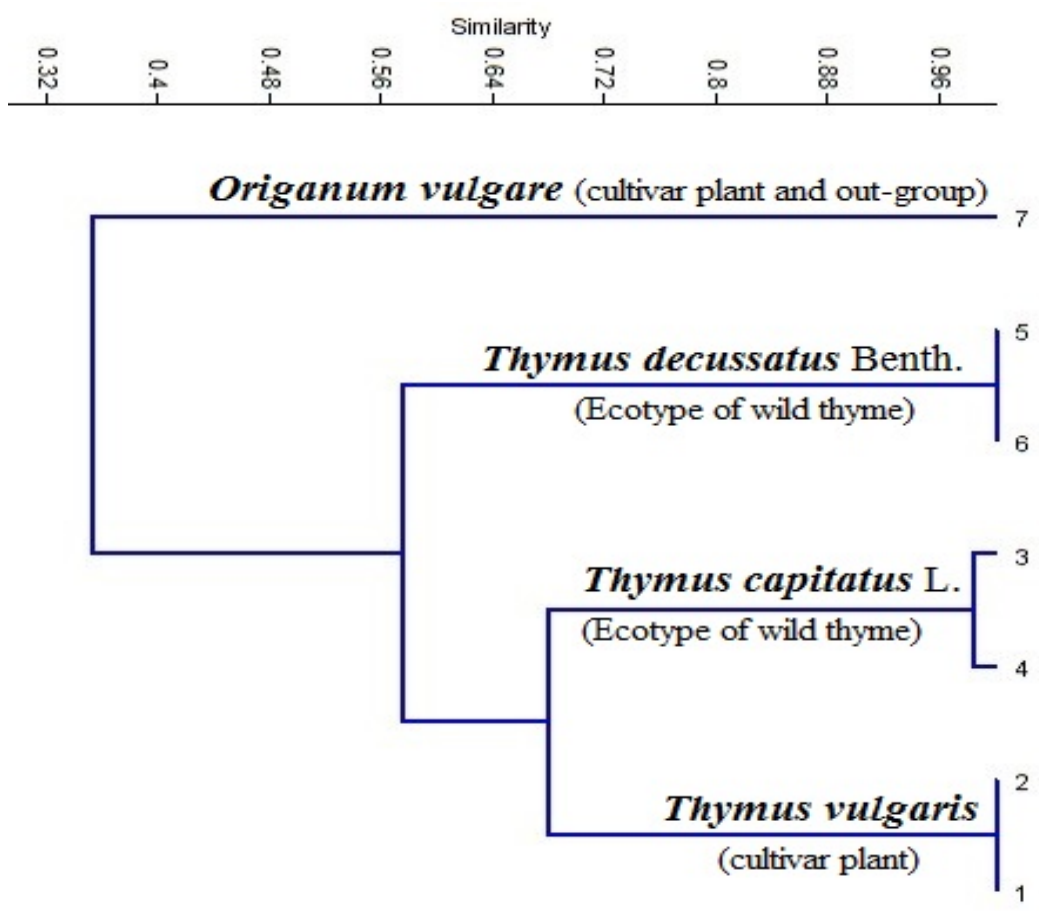

Fig. (4). The dendrogram cluster tree was generated for Thymus species, where Origanum vulgare was used as an outgroup based on RAPD. (1 and 2) Thymus vulgaris, (3 and 4) Thymus capitatus, (5 and 6) Thymus decussatus and (7) Origanum vulgare.

\section{CONCLUSION}

In this study, molecular tools could be much reliable for measuring the genetic relationship among Thymus species. Using twenty ISSR primers and fifteen of RAPD were found to generate relatively high level of DNA polymorphism among the three Thymus species. The results obtained in this study, might suggest that these chosen primers, which was screened in ISSR and RAPD tests were able to generate polymorphic bands on most genetic diverse loci among the Thymus species as proved by Tonk et al. (2010).

These results were considered to be promising for future specific DNA fingerprinting studies on Thymus species variants; suggesting to researchers to use them for specific detection of these species or expanding that work on other medicinal plants.

In general, ISSR and RAPD procedures were able to clearly distinguish the different selected Thymus species subjected to this study and also, could be potentially used for identifying Thymus species from any mixed Egyptian J. Desert Res., 69, Special Issue, 91-106 (2019) 
populations. A similar approach had been successfully used for molecular diagnosis of several species and cultivars by many other researchers (Sosinski and Doucher, 1996). Also, these markers could be used as a method of choice for identifying components for herbal medicine complex, since ISSR and RAPD techniques had been used for the determination of different components presented in herbal formulation. So, these will contribute significantly in quality control and give information about genomic variability below the species level (Williams et al., 1990), they provide relatively quick results, less time-consuming and low expensive (Arif et al., 2010).

These results can be further used to manipulate genetic determinants of horticulturally important traits and to characterize the basis of productivity of Thymus. ISSR and RAPD markers were proved to be useful tools in germplasm characterization and diversity analysis of Thymus, and can be used beside other molecular markers as AFLP and SSRs. Therefore, these findings provide guidance for identification of Thymus species, and help in their subsequent management and utilization in sustainable ways to combat human and natural pressures on these valuable natural resources. Finally, the genetic variation data would be very useful for improvement of Thymus species through conventional breeding programs as well as molecular breeding approaches such as marker assisted selection.

\section{ACKNOWLEDGEMENT}

The authors would like to express their special gratitude to Prof. Dr. Fareda Elsaied, Prof. of Genetics, Desert Research Center for the financial support and providing facilities and encouraging throughout. The authors also extend their gratitude to Academy of Scientific Research and Technology (ASRT) - Technology and Scientific Cooperation between Egyptian and Moroccan program. Project node no. is 10-2-11 (Valorization and conservation of medicinal and aromatic plants using biotechnology techniques: a case of wild endemic Thyme in Egypt and Morocco).

\section{REFERENCES}

Agostini, G., S. Echeverrigaray and T.T. Souza-Chies (2010). Genetic diversity of endangered Brazilian endemic herb Cunila menthoides Benth. (Lamiaceae) and its implications for conservation. Biochem. Sys. Ecol., 38: 1111-1115.

Egyptian J. Desert Res., 69, Special Issue, 91-106 (2019) 
Akcin, A.T. (2006). Numerical taxonomic studies on some species of the genus Thymus L. (Labiatae) in Turkey. Asian Journal of Plant Science, 5 (5): 782-788.

Alamdary, S.B.L., A. Safarnejad and M. Rezaee (2011). Evaluation of genetic variation between Thymus accessions using molecular markers. J. Basic. Appl. Sci. Res., 1 (12): 2552-2556.

Baigi, M.N.R., S. Grewal and S. Dhillon (2009). Molecular characterization and genetic diversity analysis of citrus cultivars by RAPD markers. Turk. J. Agric. For., 33: 375-384.

Casiva, P.V., B.O. Saidman, J.C. Vilardi and A.M. Cialdella (2002). First comparative phenetic studies of argentinean species of Acacia (Fabaceae), using morphometric, isozymal and RAPD approaches. Am. J. Bot., 89: 843-853.

Jaccard, P. (1908). Nouvelles recherches sur la distribution forale. Bulletin de la Société Vaudoise des Sciences Naturelles, 44: 223-270.

Khalil, R. and Z. Li (2012). Determination of genetic variation and relationship in Thymus vulgaris populations in Syria by random RAPD markers. Plant Biosystems, 146: 217-225.

Li, F. and N. Xia (2005). Population structure and genetic diversity of an endangered species, Glyptostrobus pensilis (Cupressaceae). Bot. Bull. Acad. Sin., 46: 155- 162.

Mariette, S., E. Balsemin, S. Stoeckel, M. Tavaud, H. Le Bouler, F. Santi and M. Verger (2007). Parental participation in progeny and effective population sizes in experimental seed orchards of wild cherry Prunus avium L. (Batsch). Ann. Fores. Sci., 64: 533-539.

Monteleone, I., D. Ferrazzini and P. Belletti (2006). Effectiveness of neutral RAPD markers to detect genetic divergence between the subspecies uncinata and mugo of Pinus mugo Turra. Silva Fennica, 40: 3.

Morales, R. (1996). Studies on the genus Thymus L. Lamiales Newsletter, 4: 6-8.

Mulcahy, D.L., M. Cresti, H.F. Linskens, C. Intrieri, O. Silverstoni, R. Vignani, and M. Pancaldi (1995). DNA fingerprinting of Italian grape varieties: a test of reliability in RAPDs. Advanced Horticultural Science, 9: 185-187.

Nybom, H. and K. Weising (2007). DNA profiling of plants. Medicinal Plant Biotechnology, 9: 73-95.

Ruana, C., P. Qin, J. Zheng and Z. Hea (2004). Genetic relationships among some cultivars of sea buckthorn from China, Russia and Mongolia based on RAPD analysis. Sci. Hort., 101: 417-426.

Solouki, M., H. Mehdikhani, H. Zeinali and A.A. Emamjomeh (2008). Study of genetic diversity in Chamomile (Matricaria chamomilla) based on morphological traits and molecular markers. Sci. Hort., 117: 281-287.

Egyptian J. Desert Res., 69, Special Issue, 91-106 (2019) 
Sosinski, B. and D.S. Douches (1996). Using polymerase chain reaction-based DNA amplification to fingerprint North American potato cultivars. Hort. Sci., 31: 130-133.

Sunar, S., O. Aksakal, N. Yildirimi, G. Agar, M. Gulluce and F. Sahin (2009). Genetic diversity and relationships detected by FAME and RAPD analysis among Thymus species growing in eastern Anatolia region of Turkey. Romanian Biotechnological Letters, 14: 4313-4318.

Tonk, A.F., S. Yu“ce, E. Bayram, R.R. Akc, A. Giachino, C. So“nmez, I. Telci and M.A. Furan (2010). Chemical and genetic variability of selected Turkish oregano (Origanum onites L.) clones. Plant Syst. Evol., 288: 157-165.

Trindade, H., M.M. Costa, S.B. Lima, L.G. Pedro, A.C. Figueiredo and J.G. Barroso (2009). A combined approach using RAPD, ISSR and volatile analysis for the characterization of Thymus caespititius from Flores, Corvo and Graciosa islands (Azores, Portugal). Biochem. Syst. Ecol., 37: 670-677.

Tzakow, O. and T. Constantinidis (2005). Chemotaxonomic significance of volatile compounds in Thymus samius and its related species Thymus atticus and Thymus parnassicus. Biochem. Syst. Ecol., 33: 11311140. 
التنوع الوراثي بين أنواع الزعتر باستخدام علامات RAPD و إسراء عطية الثربيني"، الثيماء سعد الدمرداش، ياسر عبد الحكيم محمد سلامة ومحمد ذو الققار أحمد أعطد قسم الأصول الور اثية، مركز بحوث الصحر اء، القاهرة، المطرية، مصر

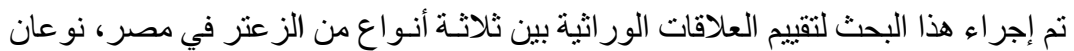

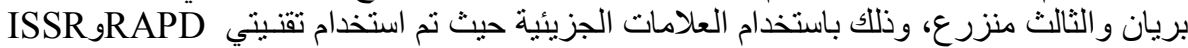

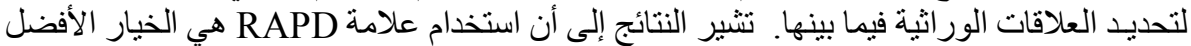

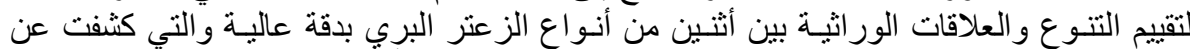

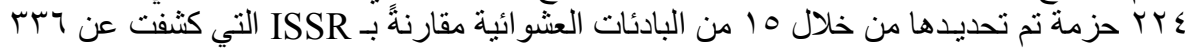

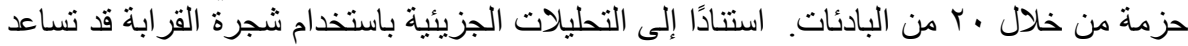

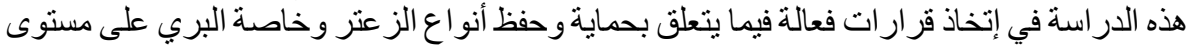

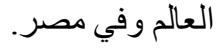

Egyptian J. Desert Res., 69, Special Issue, 91-106 (2019) 